\title{
POR UMA VISÃO HUMANISTA E UNIVERSITÁRIA DO DIREITO
}

(Aula Inaugural do ano acadêmico de 2007)

\author{
FOR AN HUMANIST AND ACADEMIC VISION OF THE LAW
}

Ignacio Maria Poveda Velasco ${ }^{1}$

Excelentíssimo Sr. Prof. Titular João Grandino Rodas, DD. Diretor da Faculdade de Direito da Universidade de São Paulo;

Excelentíssimo Sr. Prof. Associado Sérgio Resende de Barros, Presidente da Comissão Organizadora da Semana de Recepção aos Calouros de 2007, em nome de quem saúdo todos os membros do corpo docente aqui presentes;

Sras. funcionárias, funcionários, alunas, alunos, familiares, amigos..., que nos honram com a sua presença;

Caras calouras e calouros!

A minha exposição constará de duas partes: na primeira, de caráter histórico, apresentarei um panorama - à guisa de resgate, em certos aspectos, inédito - do que foi a primeira aula inaugural na vida da nossa Academia. Na segunda, numa perspectiva jusfilosófica, tecerei algumas reflexões sobre o que poderia ser considerada uma visão humanista e universitária do Direito.

No próximo dia 11 de agosto comemoraremos, como é do conhecimento de todos, os 180 anos da fundação dos Cursos Jurídicos no Brasil.

Por insistência do Visconde de São Leopoldo, ${ }^{2}$ paulista natural de Santos, justamente homenageado nesta Faculdade com um belo espaço, próximo a este Salão

\footnotetext{
Professor Titular de História do Direito da Faculdade de Direito da Universidade de São Paulo.

2 José Feliciano Fernandes Pinheiro, Visconde de São Paulo, formou-se em Direito em Coimbra, em 1798. Após três anos de trabalho como magistrado em Lisboa, retornou ao Brasil, tendo sido nomeado juiz das Alfândegas do Rio Grande do Sul e Santa Catarina. Auditor militar, historiador e político, foi eleito deputado das Cortes Gerais e Constituintes da Nação Portuguesa, como representante das Províncias de São Paulo e de São Pedro (mais tarde, Província do Rio Grande do Sul). Voltando ao Brasil, foi novamente eleito deputado, desta vez para representar São Paulo na Assembléia Constituinte do Brasil. Ocupou diversos cargos políticos como o de Presidente da Província de São Pedro e, de 1825 a 1827, por nomeação de D. Pedro I, o de Ministro e Secretário dos Negócios do Império, em cujas funções teve papel decisivo para a assinatura da Carta de Lei de 11 de agosto de 1827. Cf. VAMPRÉ, Spencer. Memórias para a história da Academia de São Paulo. São Paulo: Saraiva, 1924. v. 1, p. 42-45.
} 
Nobre, no qual nos encontramos, o Imperador D. Pedro I assinava, nesse mesmo dia do ano de 1827, Carta de Lei criando dois Cursos Jurídicos, um em São Paulo e outro em Olinda. ${ }^{3}$

Encarregado pelo Governo Imperial de implementar na Capital paulista o Curso recém-criado, o Tenente-General José Arouche de Toledo Rendon, ${ }^{4}$ decidiu, após diligentes gestões, propor a sua instalação no Convento que os franciscanos possuíam no Largo de São Francisco.

Aqui instalados desde $1647,{ }^{5}$ os frades, reduzidos ao número de seis quando dos fatos de que ora nos ocupamos, ${ }^{6}$ habitavam um convento grande, para os padrões da época, com amplos espaços e salões.

$\mathrm{Na}$ descrição que o Diretor do Curso Jurídico faz ao Visconde de São Leopoldo, em Ofício datado aos 20 de novembro de 1827, o prédio contava, no andar superior, com "um salão antigo e outro sumamente grande, em paralelogramo, destinado para celas", o primeiro servindo "sofrivelmente para uma aula", e do segundo podendo se formar duas. Dá conta, também, da existência, nesse mesmo pavimento, de "uma boa

3 Ver a íntegra do referido diploma in SEGURADO, Milton Duarte. O direito no Brasil. São Paulo: Bushatsky; Edusp, 1973. p. 335-336.

4 Nascido em São Paulo no ano de 1756, doutorou-se em leis em Coimbra em 03 de julho de 1779. De volta ao Brasil, dedicou-se à advocacia, exerceu cargos de magistrado e, mais tarde, seguindo a tradição paterna, fez brilhante carreira militar, até alcançar o título de marechal de campo. Constituinte na Assembléia de 1823 e deputado integrante da primeira legislatura (de 1826 a 1830), foram inúmeros os serviços por ele prestados à Cidade e à antiga Província de São Paulo, vindo a falecer em sua cidade natal aos 26 de junho de 1834. Cf. NOGUEIRA, José Luís de Almeida. A Academia de São Paulo: tradições e reminiscências (estudantes, estudantões, estudantadas). 3. ed. São Paulo: Saraiva, 1977. v. 1, p. 32. Ver, também, MARQUES, Manuel Eufrásio de Azevedo. Apontamentos históricos, geográficos, biográficos, estatísticos e noticiosos da Província de São Paulo. Rio de Janeiro: Typographia Universal de Eduardo e Henrique Laemmert, 1879. v. 1, p. 33-34.

5 Almeida Nogueira afirma ter sido o convento fundado por Frei Francisco dos Santos em 1640, e concluído em 1644. Cf. NOGUEIRA, José Luís de Almeida. op. cit., p. 40. Contudo, em seu bem documentado trabalho sobre a história da nossa Faculdade, Ana Luiza Martins e Heloisa Barbuy afirmam, com base no trabalho de (RÖWER, Basílio. Páginas da história franciscana no Brasil. Petrópolis: Vozes, 1941), que o mesmo foi concluído em 1647, sendo a Igreja de São Francisco um pouco anterior, de 1643, e a da Ordem Terceira da Penitência do Seráfico Pai São Francisco, de 1676. De acordo com as referidas autoras, Frei Francisco dos Santos fora nomeado em 1639 prelado fundador, com a incumbência de erguer um edifício ao lado da igrejinha de Santo Antônio, na atual Praça do Patriarca, projeto este abandonado quando, em 24 de dezembro de 1642, a Câmara de São Paulo fez aos frades doação de um amplo terreno "para a banda do rio Anhangabaú", local onde foi finalmente levantado o conjunto franciscano, compreendendo o convento e as duas igrejas (Cf. MARTINS, Ana Luiza; BARBUY, Heloisa. Arcadas: história da Faculdade de Direito do Largo de São Francisco 1827-1997. São Paulo: BMF; Alternativa, 1998. p. 16-17).

6 Nesse sentido, ver Carta de José Arouche de Toledo Rendon, diretor do Curso Jurídico de São Paulo, ao então Ministro e Secretário dos Negócios do Império, Pedro de Araújo Lima, datada de 09 de junho de 1828, in NOGUEIRA, José Luís de Almeida. op. cit., p. 47-49. 
livraria, que me parece já tem 5 mil volumes", a qual funcionava, desde 1825, como biblioteca pública da Cidade de São Paulo. ${ }^{7}$

Nos baixos do convento entendia ele poderem se estabelecer " 4 aulas menores, formando-se duas da antiga aula dos frades, e outras duas do lugar onde está a sacristia, mudando-se esta para o lugar antigo, por detrás da capela-mor (...)”. Dessa forma, conclui, "ter-se-á acomodado o Curso Jurídico com três aulas em cima e com quatro em baixo para os estudos preparatórios". ${ }^{8}$

$\mathrm{Na}$ avaliação de Arouche Rendon, "sendo do agrado de S. Majestade Imperial”, e feitas as despesas de adaptação, que ele calculava pequenas, o Curso Jurídico poderia ter princípio no ano de 1828, desde que fossem os lentes nomeados e diligenciados os atos necessários para inscrição dos interessados e para a realização dos exames preparatórios.

Portaria do novo Ministro e Secretário de Estado dos Negócios do Império, o Sr. Pedro de Araújo Lima, datada no Rio de Janeiro aos 27 de novembro de 1827, mandava o Vice-Presidente da Província de São Paulo, com base na Carta de Lei de 11 de agosto, se entender "com os Religiosos Franciscanos para se abrir a Aula do primeiro anno em uma sala que tenha dimensoens necessarias no edificio que elle occupão, e para darem as casas, que forem precisas, para o archivo, e mais serviço do mesmo estabelecimento (...)". ${ }^{9}$

\footnotetext{
Sobre isto, ver o interessante trabalho de BEFFA, Maria Lucia; NAPOLEONE, Luciana Maria. Da primeira biblioteca pública oficial da Província de São Paulo à Biblioteca da Faculdade de Direito da USP: história da biblioteca de suas origens até a criação da USP. In: BITTAR, Eduardo Carlos Bianca (Org.). História do direito brasileiro: leituras da ordem jurídica nacional. São Paulo: Atlas, 2003. p. 171-186.

8 Cf. NOGUEIRA, José Luís de Almeida. op. cit., p. 36-38. Por conta da queda do Gabinete de que fazia parte o Visconde São Leopoldo, ocorrida na data do mencionado ofício de 20 de novembro, o Arouche Rendon endereçou outro ofício, em 02 de dezembro desse mesmo ano, ao novo Ministro, Sr. Pedro de Araújo Lima, dando conta de suas diligências e concluindo que o arranjo se faria "sem incômodo dos frades, aos quais resultará o proveito de alguns reparos do edifício, que se devem fazer pela Fazenda Pública". Id. Ibid., p. 39. De fato, a Academia começou suas atividades ocupando apenas três das quatro salas do térreo. Só em agosto de 1828 é que se deu a cessão formal do Convento, comunicada pelo Ministro ao Diretor, por ofício de 21 daquele mês e ano. Contudo, a desocupação total e efetiva do prédio pelos frades só ocorreu no início de 1829 . Sobre isto, ver a correspondência reproduzida por Almeida Nogueira, às p. 47-52 da supramencionada obra.

9 Cf. O FAROL Paulistano, n. 72, de 15 de dezembro de 1827, consultado por cópia microfilmada existente no Arquivo do Estado de São Paulo. Esse jornal foi-nos de grande utilidade para reconstruir muitos fatos, relacionados com a instalação da Academia de São Paulo e a inauguração de suas atividades, ocorridos após a promulgação da Carta de Lei de 11 de Agosto de 1827.
} 
Concluía o Ministro, dando conta da expedição, nessa mesma data, de ofícios para o Tesouro, com as competentes ordens de pagamento "de todas as despesas relativas à abertura, e ao andamento do referido Curso Jurídico." 10

Encaminhadas as providências materiais, começaram também a ser tomadas medidas outras para a implementação do Curso. Assim, em 19 de dezembro desse ano de 1827, é publicado no Rio de Janeiro Edital convocando à Diretoria de Estudos da Corte, os "pretendentes das Cadeiras de Estudos Preparatórios", que não estivessem já providas em São Paulo e Olinda, para prestar concurso. ${ }^{11}$

Por sua vez, o presidente da Província de São Paulo, Thomaz Xavier Garcia de Almeida, "Official da Imperial Ordem do Cruzeiro, Desembargador da Relação da Bahia", publicava, a 24 de janeiro de 1828, outro Edital com o seguinte teor: "Faço saber, que de ordem de SUA MAGESTADE O IMPERADOR, e execução da Carta de Lei de onze de agosto de mil oitocentos e vinte sete, se há de impreterivelmente abrir em o principio de Março próximo a Aula do primeiro anno do Curso Jurídico creado n'esta Capital: todas as pessoas, que se quizerem matricular deverão concorrer até o fim do mez de Fevereiro, a fim de poderem com tempo ser examinados nos Estudos preparatórios, cujos exames Manda O Mesmo Augusto Senhor, que se principiem quinze dias pelo menos antes da abertura, das Aulas Maiores; o que para constar, e para que chegue à notícia de todos mandei lavrar o presente, que vai por mim assignado e sellado com o Sello das Armas do Império. Palácio do Governo de S. Paulo 24 de Janeiro de 1828". ${ }^{12}$

O Diretor do novo Curso fazia, também, a sua parte, determinando em $1^{\circ} \mathrm{de}$ fevereiro que "os Exames das Sciencias preparatórias para a matrícula, hão-de principiar no dia 11 do corrente mez. Os Pertendentes [sic] deverão dirigir-se ao mesmo Director para lhes assignar o dia e a hora do Exame". ${ }^{13}$

Para a reconstituição do ambiente da Cidade, naquelas semanas que antecederam a inauguração da nossa Academia, bem como para o resgate de fatos interessantes e importantes, que não vêm narrados em estudos tradicionais sobre a matéria, como os de Almeida Nogueira e Spencer Vampré, foi-nos de grande utilidade a consulta a

10 O FAROL Paulistano, n. 72, 15 de dezembro de 1827. Por ofício de 14 de janeiro de1828, o Ministro ordenava ao Presidente da Província de São Paulo que mandasse proceder logo aos consertos indispensáveis no convento de São Francisco, "para que não se retardasse a abertura das aulas". Cf. NOGUEIRA, José Luís de Almeida. op. cit., p. 40.

11 Cf. O FAROL Paulistano, n. 77, de 05 de janeiro de 1828.

${ }^{12}$ Cf. O FAROL Paulistano, n. 85, de $1^{\circ}$ de fevereiro de 1828.

${ }^{13}$ Cf. O FAROL Paulistano, n. 86, de 06 de fevereiro de 1828. 
Por uma visão humanista e universitária do Direito

(Aula Inaugural do ano acadêmico de 2007)

O Farol Paulistano, primeiro periódico impresso de São Paulo, que circulou entre os anos de 1827 e $1833 . .^{14}$

Da sua leitura ficamos sabendo da chegada, no dia 13 de fevereiro, do "lente" do $1^{\circ}$ ano do Curso Jurídico, o Sr. José Maria de Avelar Brotero, nomeado que fora pelo Decreto de 12 de outubro de 1827, para reger a cadeira de Direito Natural. ${ }^{15}$

É curioso o comentário que a respeito dele faz José da Costa Carvalho, redator do jornal: "Nada podemos diser acerca dos conhecimentos do Sr. Brotero, mas temos que sérão sufficientes para o desempenho dos seus dificeis deveres; e que o tempo, o estudo e a pratica de ensinar o tornarão habillisimo, pois nos consta, que tem não vulgar talento, e assim ouvimos affirmar na Universidade de Coimbra, cujo aluno foi, e foi nosso contemporâneo". ${ }^{16}$

Esse mesmo Costa Carvalho mostra-se entusiasmado com as perspectivas do Curso e comenta que os futuros alunos são muito bons, pois tivera oportunidade de acompanhar os exames de alguns deles, pelo que afirma sem hesitação que "nos encherão de gosto, e de esperanças." E conclui: "A mocidade Brazileira sempre em toda parte gosou de créditos scientíficos, e a Paulistana em nada desmerece, antes pelo contrario figura bem por seus talentos, e por sua moral". ${ }^{17}$

\footnotetext{
${ }^{14}$ Tal periódico foi fundado pelo Dr. José da Costa Carvalho, mais tarde Barão, Visconde e Marquês de Montealegre. Formado em Direito na Universidade de Coimbra, foi, como deputado por São Paulo, paladino da reação liberal à política de desmandos e de absolutismo de D. Pedro I. Integrou a Regência Trina de 1831 a 1835. Em 1841 desempenhou-se como Presidente da Província de São Paulo e, em outubro do ano seguinte, tornou-se chefe do $9^{\circ}$ gabinete ministerial, com a renúncia de Francisco de Paula Souza e Mello da presidência do Conselho. Foram redatores de $O$ Farol, junto com Costa Carvalho, Antonio Mariano de Azevedo Marques, cognominado o Mestrinho, Manoel Joaquim do Amaral Gurgel, Vicente Pires da Motta e Nicolau Pereira de Campos Vergueiro, entre outros. Cf. Resenha dos jornais publicados na capital de S. Paulo a partir de 1823. FREITAS, Affonso A. de. A imprensa periódica de São Paulo. Revista do Instituto Histórico e Geográfico de São Paulo, São Paulo, v. 19, p. 342-347, 1914. Natural de Salvador da Bahia, José da Costa Carvalho fixouse em São Paulo, onde contraiu matrimônio com D. Genebra de Barros Leite, de importante e conceituada família paulistana. Por decreto de 05 de novembro de 1835, foi nomeado Diretor do Curso Jurídico de São Paulo, cargo no qual permaneceu por pouco mais de seis meses. Nesse sentido, ver FERREIRA, Waldemar (Comp.). A Congregação da Faculdade de Direito de São Paulo na centúria de 1827 a 1927. Notas compiladas e coordenadas pelo Dr. Waldemar Ferreira, professor cathedratico de Direito Commercial. Separata da: Revista da Faculdade de Direito de São Paulo, São Paulo, v. 24, p. 10-11, 1928.

15 José Maria de Avelar Brotero, natural de Lisboa, onde nasceu em 1789, formou-se em Direito em 1820 na Universidade de Coimbra. Obrigado a deixar Portugal por suas idéias políticas de cunho liberal, teve uma rápida passagem pelos Açores antes de se fixar, em 1825, no Rio de Janeiro, onde exerceu a advocacia. Naturalizou-se cidadão brasileiro em 1833. Cf. NOGUEIRA, José Luís de Almeida. op. cit., p. 34-35. Ver, também, BLAKE, Augusto Victorino Alves Sacramento. Diccionario bibliographico brazileiro. Rio de Janeiro: Typographia Nacional, 1899. v. 5, p. 37-38.

${ }^{16}$ Cf. O FAROL Paulistano, n. 89, de 16 de fevereiro de 1828.

${ }^{17}$ Id. Ibid.
} 
No dia 15 de fevereiro, o Secretário interino do Curso, Ildefonso Xavier Ferreira, anuncia que as matrículas dos estudantes terão lugar até o último dia do mês de março. ${ }^{18}$ Logo depois, em 26 de fevereiro, presumivelmente com os exames preparatórios já realizados, a Diretoria fixa para o dia 03 de março o início das mesmas, devendo para isso pagar uma taxa de matricula e comprovar a idade mínima de 15 anos, bem como a aprovação nos exames preparatórios, tudo nos termos do art. $8^{\circ}$ da Carta de Lei de 11 de agosto de $1827 .{ }^{19}$

No número 91 do jornal, correspondente à quarta-feira 27 de fevereiro de 1828, aparece estampado o seguinte anúncio:

"Pela Diretoria do Curso Jurídico se faz público que a abertura do mesmo será no dia $1^{\circ}$ de Março pelas 4 horas da tarde."20

Podemos imaginar como deve ter sido grande, na pacata São Paulo daquela época, com seus aproximadamente 15 mil habitantes, ${ }^{21}$ a excitação daqueles dias e a expectativa pela inauguração. Convites foram distribuídos, arrumações de última hora levadas a termo, providências de todo tipo tomadas. E, assim, chegou o grande dia...: era um sábado.

Deixemos $O$ Farol Paulistano nos contar:

“Dia $1^{\circ}$ de Março de 1828! Tú abres uma nova Épocha nos annaes do Brasil! Tú vens firmar e como sellar a nossa Independencia Política! Tú rivalizas com o imortal DIA SETE DE SETEMBRO de 1822! Nem era justo que a primeira Cidade do Brasil que ouvio o grito de INDEPENDENCIA deixa-se de ser o berço das Sciencias Sociaes,

\footnotetext{
${ }_{18}$ O FAROL Paulistano, n. 89, de 16 de fevereiro de 1828.

${ }^{19} \mathrm{O}$ comunicado excetuava a apresentação da certidão de aprovação em geometria, ao que parece pela falta, naquele momento, de pessoas com habilitação para tal. Contudo, ressaltava que os alunos deveriam fazer esse exame até o fim do curso, "sem o qual não serão admittidos à Formatura". Cf. O FAROL Paulistano, n. 92, de $1^{\circ}$ de março de 1828. Segundo Ana Luiza Martins e Heloisa Barbuy, no ano 1828, o médico italiano de idéias liberais Giovanni Battista Libero Badaró, ferrenho opositor dos assim entendidos desmandos absolutistas do nosso jovem Imperador, lecionou graciosamente geometria no Curso Preparatório da Academia de Direito de São Paulo. No ano seguinte, ao solicitar do governo uma remuneração pelo serviço prestado, a mesma lhe foi negada. Discute-se se a razão para tal teria sido de ordem ideológica. Líbero Badaró foi assassinado em 1830, tornando-se no imaginário da época o "mártir da liberdade". Cf. MARTINS, Ana Luiza; BARBUY, Heloisa. op. cit., p. 35-37.

${ }^{20}$ Cf. O FAROL Paulistano, n. 91, de 27 de fevereiro de 1828. As aulas, contudo, devem ter começado no dia 10 de março, conforme determinado pelo Sr. Diretor: "Finalmente [se faz público] que no dia 10 do mesmo mez principia a ter exercício a Cadeira d'este $1^{\circ}$ anno, a qual terá princípio às 8 horas da manhã até 9 e meia, marcadas pelo relógio e sino do Convento de S. Francisco. S. Paulo, 26 de Fevereiro de 1828". Cf. O FAROL Paulistano, n. 92, de $1^{\circ}$ de março de 1828.

${ }^{21}$ Cf. AZEVEDO, Vicente de Paulo Vicente de. José Arouche de Toledo Rendon: $1 .^{\circ}$ director da Academia de Direito. Revista da Faculdade de Direito, São Paulo, v. 31, p. 474, 1935. Antonio Gontijo de Carvalho afirma que São Paulo contava com, aproximadamente, 20 mil almas e "uma arrecadação de pouco mais de duzentos contos de reis". Cf. CARVALHO, Antonio Gontijo de. Visconde de Congonhas do Campo (18-10-1767 a 1010-1851): notas biográficas. Digesto Econômico, São Paulo, ano 9, n. 101, p. 56, abr. 1953.
} 
destinada a acolher em seu seio a mocidade das Províncias meridionaes do Brasil, e infundir-lhes com os conhecimentos litterarios o espirito d'heroismo, que em todas as épochas tem caracterisado os seus filhos.

"Faltão-nos as expressões para expôr-mos aos nossos leitores a pompa e magnificência com que no $1^{\circ}$ de Março se abrio o Curso-Juridico; e darmos uma idéia da enérgica e eloquentissima Oração do Sr. Dr. José Maria Brotero. - Às 4 horas da tarde, como fora determinado, concorreu immenso Pôvo ao Convento de S. Francisco. A salla destinada para a Aula, que tem 90 palmos de comprimento, estava apinhada de gente; até muitas das principaes Senhoras d'esta Cidade, tendo sido convidadas, assistirão este acto brilhantissimo. O Lente recitou um bem traçado discurso do qual daremos no próximo número copiosa noticia". ${ }^{22}$

E prossegue o jornal em sua narrativa pormenorizada de tão importante acontecimento para a história de São Paulo e do Brasil:

"Finda a oração dirigirão-se todos à Igreja, onde o Padre Mestre Guardião fez cantar um Te Deum em Ação de Graças. Depois foram todos convidados pelo Exmo. Director para servirem-se de doces e refrescos, que para isso estavão preparados numa esplendida e riquissima meza, a qual esteve franca a todo o Pôvo. Ai recitarão-se algumas Odes, e cantou-se um Hymno composto para solemnisar este acto. S. Exca. Reverendíssima fez cantar na Cathedral no dia 2 ao meio dia um Solemne Te Deum.

"Toda a Cidade se illuminou espontaneamente nas noites do $1^{\circ}, 2^{\circ}$ e $3^{\circ}$.

"Foi assim que o Povo d'esta Capital deu uma prova de seu regosijo, e de quanto sabe apreciar em seu justo valor este sucesso que, promettendo ao Brasil todo immensas vantagens, é para esta Província um manancial de Felicidade". ${ }^{23}$

Foi, assim..., com esse tom de verdadeiro acontecimento histórico, que foi vivida a primeira Aula Inaugural da nossa Escola.

Algo se pode dizer sobre o local em que ela ocorreu. ALMEIDANOGUEIRA afirma que a tal sala de "90 palmos", a que faz referência $O$ Farol Paulistano, era a sala n. 2 do antigo edifício (demolido em meados da década de 1930), sala essa situada na parte posterior do convento, mais ou menos onde hoje está localizada a sala João Mendes Jr., e que tinha sido formada, conforme a proposta de Arouche Rendon, a partir da divisão da sacristia do antigo convento. ${ }^{24}$

${ }^{22}$ Cf. O FAROL Paulistano, n. 93, de 05 de março de 1828.

${ }^{23}$ Id. Ibid.

${ }^{24}$ Cf. NOGUEIRA, José Luís de Almeida. op. cit., p. 43. Na nota 4 à p. 37 da referida obra, Carlos Penteado de Rezende, comentando o texto de Almeida Nogueira, afirma que o antigo edifício existiu até cerca de 1933, 
Quanto à assistência, além das numerosas senhoras da sociedade referidas pelo Farol, estavam presentes o Presidente da Província, Thomaz Xavier Garcia de Almeida, o Bispo diocesano, D. Manuel Joaquim Gonçalves de Andrade, autoridades civis e eclesiásticas, e..., presumivelmente, estudantes e familiares. ${ }^{25}$

Que estudantes? Quantos eram?

Foram inicialmente 27 os alunos matriculados, mas chegaram a 33 até o fim daquele mês de março de 1828: 17 paulistas ( 9 da Capital e 8 de cidades do litoral ou do interior, como Iguape, São Sebastião, Sorocaba e Porto Feliz), 10, do Rio de Janeiro, 4, de Minas Gerais e 2, da Bahia. ${ }^{26}$

Deles, uns, como o paulista Manuel Dias de Toledo, aqui se tornaram professores, ${ }^{27}$ outros, como Vicente Pires da Motta e Manoel Joaquim do Amaral Gurgel, ambos paulistanos, além de mestres, chegaram a ser diretores da Escola; ${ }^{28}$ e, ainda, vários outros, como José Antonio Pimenta Bueno, também paulistano, tiveram atuação destacada na vida política e diplomática do País. ${ }^{29}$

e que "o atual prédio em que funciona a Faculdade começou a ser construído sendo diretor o dr. Alcântara Machado". Sobre a sala na qual foi realizada a primeira Aula Inaugural ver, também, o texto de Spencer Vampré, A demolição do antigo prédio da Faculdade de Direito e as reminiscências que desperta. Revista da Faculdade de Direito, São Paulo, v. 33, fasc. 3, p. 440, 1937; e, ainda, de SEVERO, Ricardo. A casa da Faculdade de Direito de São Paulo: 1643/1937. Revista da Faculdade de Direito, São Paulo, v. 34, fasc. 1, p. $12,1938$.

${ }^{25}$ Cf. NOGUEIRA, José Luís de Almeida. op. cit., p. 45. Ver, também, VAMPRÉ, Spencer. Memórias..., cit. (nota 01), p. 49, o qual menciona, na nota 4 dessa página, que a presença das senhoras foi motivo de reclamação entre os frades.

${ }^{26}$ Cf. O FAROL Paulistano, n. 98, de 22 de março de 1828, dando notícia do bom andamento das aulas e informando que, além dos estudantes já matriculados, "mais de 5 ou 6 estão para fazer os seus exames". O Redator comunica que o jornal vai imprimir as lições para os alunos, recebendo em troca apenas o empenho deles em seu estudos. A relação completa dos 33 estudantes matriculados da primeira turma pode ser encontrada no número 104 de O Farol Paulistano, de 16 de abril de 1828: "Lista dos Estudantes matriculados no Curso Jurídico de S. Paulo no primeiro anno de mil oitocentos e vinte oito" (p. 427-428). Essa relação vem reproduzida, com erro, na Revista da Faculdade de Direito, São Paulo, v. 1, p. 196-197, 1893.

${ }^{27}$ Cf. BLAKE, Augusto Victorino Alves Sacramento. Diccionario bibliographico brazileiro. Rio de Janeiro: Imprensa Nacional, 1900. v. 6, p. 59-60. Era natural de Araritaguaba, hoje cidade de Porto Feliz, onde nasceu em 23 de abril de 1802. Tinha, portanto, 25 anos quando ingressou na Academia.

${ }^{28}$ Cf., respectivamente, BLAKE, Augusto Victorino Alves Sacramento. Diccionario bibliographico brazileiro. 1902. v. 7, p. 369-370; e Id. Diccionario bibliographico brazileiro. cit., v. 6, p. 109-111. Nascido em $1^{\circ}$ de setembro de 1799, Pires da Motta contava com 28 anos ao iniciar seus estudos. Amaral Gurgel, nascido a 08 de setembro de 1797, tinha já completado os 30 anos.

29 Cf. BLAKE, Augusto Victorino Alves Sacramento. Diccionario bibliographico brazileiro. Rio de Janeiro: Imprensa Nacional, 1898. v. 4, p. 303-304. Nascido aos 04 de dezembro de 1803, contava 24 anos completos ao ingressar no Curso Jurídico de São Paulo. Integrante dessa primeira turma foi, também, José Antonio dos Reis, paulistano vindo ao mundo em 10 de julho de 1798, que se tornou o primeiro bibliotecário da nossa Escola. Contava com 29 anos ao se matricular na Academia. Cf. BEFFA, Maria Lucia; NAPOLEONE, Luciana Maria. op. cit., p. 177. Pela amostragem aqui apresentada podemos observar que a primeira turma da Faculdade não era propriamente uma caterva de adolescentes. 
E a primeira Aula Inaugural do Curso Jurídico de São Paulo? Sobre qual tema discorreu o insigne orador de $1828 \ldots$ ?

Dele nada nos fala Almeida Nogueira, e isto por uma razão muito simples, que ele declina com toda honestidade: acompanhara a narração dos acontecimentos pela consulta à coleção de $O$ Farol Paulistano emprestada pelo Dr. Brasílio Machado, mas nela faltava o número correspondente à descrição da aula, inexistente também na Biblioteca da Faculdade. ${ }^{30}$

Da mesma forma, Spencer Vampré silencia sobre o discurso do Conselheiro Brotero, presumivelmente pela falta, também, de fontes. ${ }^{31}$

Tendo localizado o referido exemplar no Arquivo do Estado de São Paulo, graças aos bons ofícios das competentes bibliotecárias Maria Lucia Beffa e Luciana Maria Napoleone (respectivamente diretora e supervisora técnica do serviço de atendimento ao usuário da nossa Biblioteca), acreditamos poder dar neste momento uma notícia inédita sobre aquela que foi a primeira Aula Inaugural da história desta Academia.

Ouçamos a narração:

"Depois de haver conciliado a attenção e benevolencia do numeroso auditório, que o escutava; depois de ter profusa, devida, e dignamente tecido o elogio de S.M.I. que tanto na fundação d'esta Escola Jurídica mostrou empenhar-se com desvelo mais que Real na prosperidade da Nação Brasileira; depois de ter resumida, mas vivamente louvado a Assembléia Geral, de cujo seio saíra a Lei salutar, estabeleceu as seguintes proposições. $1^{a}=$ Que a aplicação aos estudos, e a cultura das sciencias, é a primeira Lei divina natural. - $2^{a}=$ Que os Governos são obrigados pela sua essência a instituir Academias, ou Universidades para a propagação das sciencias; do que resulta um bem à humanidade em geral. - $3^{a}$ Que a Nação Brasileira, além do bem geral, terá um bem particular na creação dos dois Cursos Jurídicos decretados na Carta de Lei de 11 de Agosto. - Nas demostrações d'estas proposições - continua o jornal - se fazem notáveis algumas passagens (...)".32

Brotero, como professor da cadeira de Direito Natural que era equivalente à nossa atual Introdução ao Estudo do Direito, procurava apresentar ao seu auditório, na estrutura tripartite da retórica clássica, o que ele considerava, pela cosmovisão da época, os fundamentos da ciência jurídica. Falava de um Direito Natural alicerçado na razão,

\footnotetext{
${ }^{30}$ Cf. NOGUEIRA, José Luís de Almeida. op. cit., p. 44.

${ }^{31}$ Cf. VAMPRÉ, Spencer. Memórias para a historia da Academia de São Paulo, cit., p. 49 e ss. MARTINS, Ana Luiza; BARBUY, Heloisa. op. cit., p. 3 e ss., tampouco fazem referência ao tema da aula.

${ }^{32}$ Cf. O FAROL Paulistano, n. 94, de 08 de março de 1828.
} 
cuja violação levaria o homem à ignorância, ao desprezo da inteligência, "tornando-o um mísero animal'.

A certa altura, afirmava: "A Sciencia Jurídica Social nos fornece as máximas da rasão as mais importantes,e as regras da sua conduta (...); nos mostra a nossa igualdade e liberdade (...); nos ensina que as sociedades são todas iguaes entre si, bem como os Homens também o são, isto é, que todos receberão iguaes direitos da mão da naturesa, tendo todos iguaes obrigações para com ella (...). Em uma palavra, podese dizer que a Sciencia Jurídica Social é a mesma alma da Sociedade (...). A Sciencia Jurídica Social é o maior dom que a Divindade consedeu aos mortaes". ${ }^{33}$

Não é o caso de descer aqui a maiores detalhes da exposição do Dr. Brotero. Quem tiver interesse, poderá consultar a referida fonte, agora que é do conhecimento público. ${ }^{34}$

Além disso, quem quiser se aprofundar no pensamento e na figura do primeiro orador desta Escola, pode-se socorrer do excelente trabalho de autoria de Miguel Reale, intitulado "Avelar Brotero, ou a Ideologia sob as Arcadas - O primeiro professor da Academia". ${ }^{35}$

Hoje se fala em direitos humanos e em direitos fundamentais. Direitos estes que se consideram inerentes ao todo ser humano, que são expressão e exigência da sua dignidade de pessoas humanas. Fala-se e fala-se muito, com razão... E se deveria falar mais! Porque nunca como nestes tempos que correm, a pessoa humana tem sido tão desprezada e a sua dignidade tão vilipendiada!

O que vale uma vida, diante dessa onda de violência gratuita, sem sentido, a que temos assistido em nossos dias? Como não lembrar do menino João Hélio, brutalmente arrastado pelas ruas até ser morto, no Rio de Janeiro, há poucas semanas? Razão tinha Brotero quando afirmava que, se se desrespeitam esses direitos fundamentais, o homem se torna "um mísero animal". Ou coisa pior!..., poderíamos glosar, por que o animal, afinal, segue as leis do instinto, da sua natureza, sem se ensanhar na violência covarde.

"Por uma visão humanista e universitária do Direito" foi o tema inicialmente pensado para a nossa aula de hoje... O direito é a seiva que vivifica a árvore da convivência

\footnotetext{
33 O FAROL Paulistano, n. 94, de 08 de março de 1828.

34 À guisa de apreciação final, afirma o redator no referido número: "Ainda que não queirão que o discurso, de que acabamos de dar notícia, seja um modelo de oratória (...) não se lhe poderá negar elegância em alguns pedaços, força em outros, e sentimentos bem manejados em alguns". Cf. O FAROL Paulistano, n. 94, de 08 de março de 1828 .

${ }^{35}$ Cf. REALE, Miguel. Avelar Brotero, ou a ideologia sob as Arcadas: o primeiro professor da Academia. In: . Horizontes do direito e da história. São Paulo: Saraiva, 1956. p. 195 e ss. Reale não menciona o tema sobre o qual discorreu Brotero em sua aula.
} 
social. Mas não um direito - ius - qualquer, e sim o direito da justiça: ius est autem a iustitia appelatum, ("o direito é assim chamado por derivar da justiça"), nas palavras de Ulpiano. ${ }^{36}$

Uma visão do direito que se alicerce nos valores do respeito aos outros, no compromisso pela construção de uma sociedade verdadeiramente justa, que ofereça a todos oportunidades de se desenvolverem com dignidade, na plenitude de sua condição humana.

Uma visão humanista...

Homo sum, humani nihil a me alienum puto, dizia o escritor latino Terêncio. "Sou homem; nada do que é humano me é estranho." 37 Visão humanista que leva a um direito verdadeiramente comprometido no serviço do homem, da sua plena realização, que se constitua em ferramenta efetiva para a consecução da justiça, que transcenda o formalismo vazio ou a mera técnica, tantas vezes ensinada e utilizada ... para a obtenção de interesses pequenos!

O direito é um fenômeno eminentemente social: Ubi societas, ibi ius, diziam os antigos (“onde está a sociedade, lá está o direito"). Uma ciência (a jurisprudentia dos jurisconsultos romanos, como Gaio e Papiniano, dos quais os calouros logo ouvirão falar nas aulas de Direito Romano), que trabalha com a alteridade, regulando o direito de cada qual.

Nesse particular, é bom lembrar que o direito, pelo que tem de alteridade, exige solidariedade e preocupação pelos demais. "O meu direito vai até onde começa o direito dos outros", diz a máxima jurídica. Essa postura deve ser encarnada numa conduta de autêntico respeito pelo direito dos nossos pares ao bom nome, à integridade física e moral, à liberdade em todas as suas legítimas formas de expressão... Calouros!: respeitem, tratem bem os seus colegas, os mestres e funcionários da Escola. Ponham em prática esta exigência do verdadeiro humanismo e da justiça, em todo o período dos seus estudos escolares!

O humanismo (humanitas na expressão cunhada pelos juristas romanos), evoca o sentimento da dignidade e sublimidade que é próprio da pessoa humana e a coloca por cima das demais criaturas existentes no mundo. Esse mesmo humanismo obriga o

\footnotetext{
36 DIGESTO: Ulp., Libro primo institutionum, D. 1, 1, 1 pr.

37 Publius Terentius Afer (Públio Terêncio Africano). Originário do norte da África, nasceu como escravo romano. Adaptou obras gregas da última época da chamada "Comédia Ática". Escreveu seis comédias entre os anos 166 e 160 a.C., entre as quais HEAUTONTIMORÙMENOS (“O inimigo de si próprio"), do ano 165 a. C., da qual foi tirada a frase. Cf. NORWOOD, Gilbert; DUFF, J. Wight. Escritores de Grécia y Roma. Barcelona: Gustavo Gili Editor, 1928. p. 190-192.
} 
homem a construir a própria personalidade e a educar-se, mas, principalmente, e antes de mais nada, a respeitar e favorecer o desenvolvimento da personalidade dos outros. ${ }^{38}$

Cabe ao jurista (e jurista é todo aquele que se dedica ao ius, ao direito) o dever de contribuir para a consecução de uma ordem social mais justa, mais humana, mobilizando para tal os meios ao seu alcance para resolver ou, ao menos, ajudar a resolver os grandes problemas sociais que afetam a humanidade. Calouros, não se sintam alheios a essa causa! Tomem consciência da própria responsabilidade e da necessidade de ações efetivas! Não compactuem com a cômoda posição de quem lança sobre os outros a responsabilidade pelas injustiças presentes. ${ }^{39}$ Participem das atividades de extensão que são promovidas na Faculdade, particularmente do admirável trabalho desenvolvido pelo Departamento Jurídico do XI de Agosto, e, mais recentemente, pelo Juizado Especial Cível, no atendimento à população carente.

Visão humanista que implica na afirmação de princípios como o da igualdade natural das pessoas e o da democracia, e leva ao resgate de valores como a tolerância, a solidariedade, o respeito à diversidade e, ainda, a convivência e compreensão entre pessoas de religiões, culturas e raças diversas.

"Estou convencido de que respeitando a pessoa se promove a paz - afirmava recentemente o Papa Bento XVI - e que construindo a paz põem-se as bases para um autêntico humanismo integral. Assim é que se prepara um futuro sereno para as novas gerações. $" 40$

Visão humanista que leva a sentir a preocupação com o futuro da humanidade e do entorno em que vivemos, a assumir a responsabilidade de legar às gerações vindouras um hábitat sustentável, a proteger - sem "ecochatismos" - os recursos naturais e o equilíbrio ecológico.

Visão humanista que exige um compromisso firme com a ética e a defesa da verdade, em qualquer circunstância: no convívio familiar e social, nos relacionamentos de amizade, no exercício profissional ou na atividade política.

Não é demais lembrar alguns postulados comezinhos da ética, como "o fim não justifica os meios", "não faça aos outros o que não gostaria que fizessem a você", ou aquele outro "nem tudo o que se pode, se deve fazer". Tolas máximas moralizantes? Não! E como seria diferente o mundo se as pessoas as levassem mais a sério!

\footnotetext{
${ }^{38}$ Cf. SCHULZ, Fritz. I principii del diritto romano. Firenze: G.C. Sansoni Editore, 1946. p. 164-165.

${ }^{39}$ Cf. Paulo VI, Carta Octogesima Adveniens, de 14 de maio de 1971, n. 48.

${ }^{40}$ Cf. Bento XVI, Homilia, Roma, 02 de dezembro de 2006.
} 
Compromisso com a verdade... Amicus Plato, sed magis amica veritas!, dizia Aristóteles: "Platão é meu amigo, mas a verdade é mais amiga". ${ }^{41}$ Aristóteles, discípulo de Platão, admirava o seu mestre, a profundidade de seus pensamentos e a retidão moral da sua vida, mas considerava mais importante do que tudo isso a procura da verdade - como conhecimento da natureza humana - e a sua aplicação em todos os aspectos da vida, em seus sentimentos e na sua conduta moral. Aprendamos!

Caras calouras e calouros: será missão vossa, nos próximos anos, aproveitar muito e bem a oportunidade que a sociedade lhes dá de estudar nesta Escola. Debrucemse sobre os livros de teoria geral, conheçam o Direito Positivo, aprofundem no estado da jurisprudência..., mas não percam de vista esta visão humanista do direito!

Lembrem que o Direito é uma arte. Nas elegantes palavras do jurisconsulto Celso, recolhidas por Ulpiano, ius est ars boni et aequi (o Direito é a arte do bom e do eqüitativo, do justo em concreto). ${ }^{42}$ Uma arte, uma ciência prática, e não mera técnica ou norma fria. Como ciência que é leva ao conhecimento pelas causas, ao conhecimento do homem em primeiro lugar e da sociedade na qual ele se insere.

Por isso, o verdadeiro jurista deve ter uma visão multidisciplinar, poliédrica, da existência humana: deve conhecer, em primeiro lugar, a História, mestra da vida; deve conhecer, também, Filosofia, Antropologia, Sociologia, Ciência Política, etc. É a isto que chamamos, no título desta palestra, "visão universitária do direito". Uma visão multidisciplinar, que remonta aos tempos da criação da universidade medieval e ao próprio nome - Universitas Studiorum, universalidade de estudos e conhecimentos - que essas instituições ostentaram desde aquela época. ${ }^{43}$

Assim, consideramos ser deveras conveniente que os nossos calouros procurem cursar algumas matérias na Faculdade de Filosofia, Letras e Ciências Humanas (a tradicional FFLCH) e, em tempos de globalização, também na Faculdade de Economia e Administração (FEA) e no Instituto de Relações Internacionais.

Assim fazendo, estarão a trilhar os passos de grandes mestres desta Escola, que se tornaram versados no conhecimento dessas outras ciências, e para os quais tal conhecimento representou, e representa, um diferencial no exercício de sua docência e de suas outras atividades profissionais.

\footnotetext{
${ }^{41}$ Frase atribuída ao estagirita por AMMONIUS, em sua Vida de Aristóteles. Ammonius foi um importante comentarista de Aristóteles, na Alexandria de fins do séc. V e começos do séc. VI d.C.

42 DIGESTO: Ulp., Libro primo institutionum, D. 1, 1, 1 pr.

${ }^{43}$ Cf. CORRÊA, Alexandre Augusto de Castro. A universidade medieval. Revista da Faculdade de Direito, São Paulo, v. 45, p. 292-329, 1950. Ver, também, ALVES, José Carlos Moreira. Universidade, cultura e direito romano. Revista Trimestral de Jurisprudência dos Estados, São Paulo, v. 121, p. 1-15, fev. 1994.
} 
Aproveitem, ainda, para estudar línguas estrangeiras, com a convicção de que cada uma delas é como uma porta que nos introduz num novo e insuspeitado universo cultural. Gastem o tempo com boas leituras, privilegiando os clássicos da literatura universal, que por alguma razão são clássicos!

Visão universitária significa, por fim, a consciência, que deve ser cultuada, de que formamos parte de um todo maior, que é a Universidade de São Paulo. Embora tenhamos uma história própria, aqui antes recordada, que remonta aos longínqüos tempos da nossa independência, somos hoje a Faculdade de Direito da Universidade de São Paulo. Somos USP! E se a Faculdade de Direito é motivo de orgulho - que o é! - para a Universidade toda, nós também nos enriquecemos e somos valorizados atualmente, pelo Brasil afora, por integrarmos a melhor universidade do País!

A todas e a todos, muito obrigado pela atenção!

\section{Referências}

ALVES, José Carlos Moreira. Universidade, cultura e direito romano. Revista Trimestral de Jurisprudência dos Estados, São Paulo, v. 121, p. 1-15, fev. 1994.

AZEVEDO, Vicente de Paulo Vicente de. José Arouche de Toledo Rendon: $1^{\circ}$ director da Academia de Direito. Revista da Faculdade de Direito, São Paulo, v. 31, p. 473-479, 1935.

BEFFA, Maria Lucia; NAPOLEONE, Luciana Maria. Da primeira biblioteca pública oficial da Província de São Paulo à Biblioteca da Faculdade de Direito da USP: história da biblioteca de suas origens até a criação da USP. In: BITTAR, Eduardo Carlos Bianca (Org.). História do direito brasileiro: leituras da ordem jurídica nacional. São Paulo: Atlas, 2003.

BLAKE, Augusto Victorino Alves Sacramento. Diccionario bibliographico brazileiro. Rio de Janeiro: Imprensa Nacional, 1898. v. 4, p. 303-304.

. Diccionario bibliographico brazileiro. Rio de Janeiro: Typographia Nacional, 1899. v. 5.

. Diccionario bibliographico brazileiro. Rio de Janeiro: Imprensa Nacional, 1900. v. 6.

. Diccionario bibliographico brazileiro. 1902. v. 7, p. 369-370.

CARVALHO, Antonio Gontijo de. Visconde de Congonhas do Campo (18-10-1767 a 10-10-1851): notas biográficas. Digesto Econômico, São Paulo, ano 9, n. 101, p. 54-60, abr. 1953.

CORRÊA, Alexandre Augusto de Castro. A universidade medieval. Revista da Faculdade de Direito, São Paulo, v. 45, p. 292-329, 1950. 
FERREIRA, Waldemar (Comp.). A Congregação da Faculdade de Direito de São Paulo na centúria de 1827 a 1927. Notas compiladas e coordenadas pelo Dr. Waldemar Ferreira, professor cathedratico de Direito Commercial. Separata da: Revista da Faculdade de Direito de São Paulo, São Paulo, v. 24, p. 10-11, 1928.

MARQUES, Manuel Eufrásio de Azevedo. Apontamentos históricos, geográficos, biográficos, estatísticos e noticiosos da Província de São Paulo. Rio de Janeiro: Typographia Universal de Eduardo e Henrique Laemmert, 1879. v. 1.

MARTINS, Ana Luiza; BARBUY, Heloisa. Arcadas: história da Faculdade de Direito do Largo de São Francisco 1827-1997. São Paulo: BMF; Alternativa, 1998.

NOGUEIRA, José Luís de Almeida. A Academia de São Paulo: tradições e reminiscências (estudantes, estudantões, estudantadas). 3.ed. São Paulo: Saraiva, 1977. v. 1.

NORWOOD, Gilbert; DUFF, J. Wight. Escritores de Grécia y Roma. Barcelona: Gustavo Gili Editor, 1928.

REALE, Miguel. Avelar Brotero, ou a ideologia sob as Arcadas: o primeiro professor da Academia. In: . Horizontes do direito e da história. São Paulo: Saraiva, 1956.

SCHULZ, Fritz. I principii del diritto romano. Firenze: G.C. Sansoni Editore, 1946.

SEGURADO, Milton Duarte. O direito no Brasil. São Paulo: Bushatsky; Edusp, 1973.

SEVERO, Ricardo. A casa da Faculdade de Direito de São Paulo: 1643/1937. Revista da Faculdade de Direito, São Paulo, v. 34, fasc. 1, p. 12, 1938.

VAMPRÉ, Spencer. Memórias para a historia da Academia de São Paulo. São Paulo: Saraiva, 1924. v. 1 .

. A demolição do antigo prédio da Faculdade de Direito e as reminiscências que desperta. Revista da Faculdade de Direito, São Paulo, v. 33, fasc. 3, p. 440, 1937.

FREITAS, Affonso A. de. A imprensa periódica de São Paulo. Revista do Instituto Histórico e Geográfico de São Paulo, São Paulo, v. 19, p. 342-347, 1914.

Fontes:

O FAROL Paulistano: n.72, de 15 de dezembro de 1827; n.77, de 05 de janeiro de 1828; n.85, de $1^{\circ}$ de fevereiro de 1828; n. 86, de 06 de fevereiro de 1828; n. 89, de 16 de fevereiro de 1828; n. 91, de 27 de fevereiro de 1828 ; n. 92 , de $1^{\circ}$ de março de 1828; n. 93, de 05 de março de $1828 ;$ n. 94, de 08 de março de 1828; n. 98, de 22 de março de 1828; n. 104, de 16 de abril de 1828. 
DIGESTO: Ulp., Libro primo institutionum, D. 1, 1, 1 pr.

Outras:

HEAUTONTIMORÙMENOS (“O inimigo de si próprio”), do ano 165 a. C. - Terêncio (Publius Terentius Afer).

CARTA Octogesima Adveniens, de 14 de maio de 1971, n. 48 - Papa Paulo VI.

HOMILIA, Roma, 02 de dezembro de 2006 - Papa Bento XVI.

VIDA de Aristóteles - Ammônio (Ammonius, comentarista de Aristóteles, na Alexandria de fins do séc. V e começos do séc. VI d.C). 


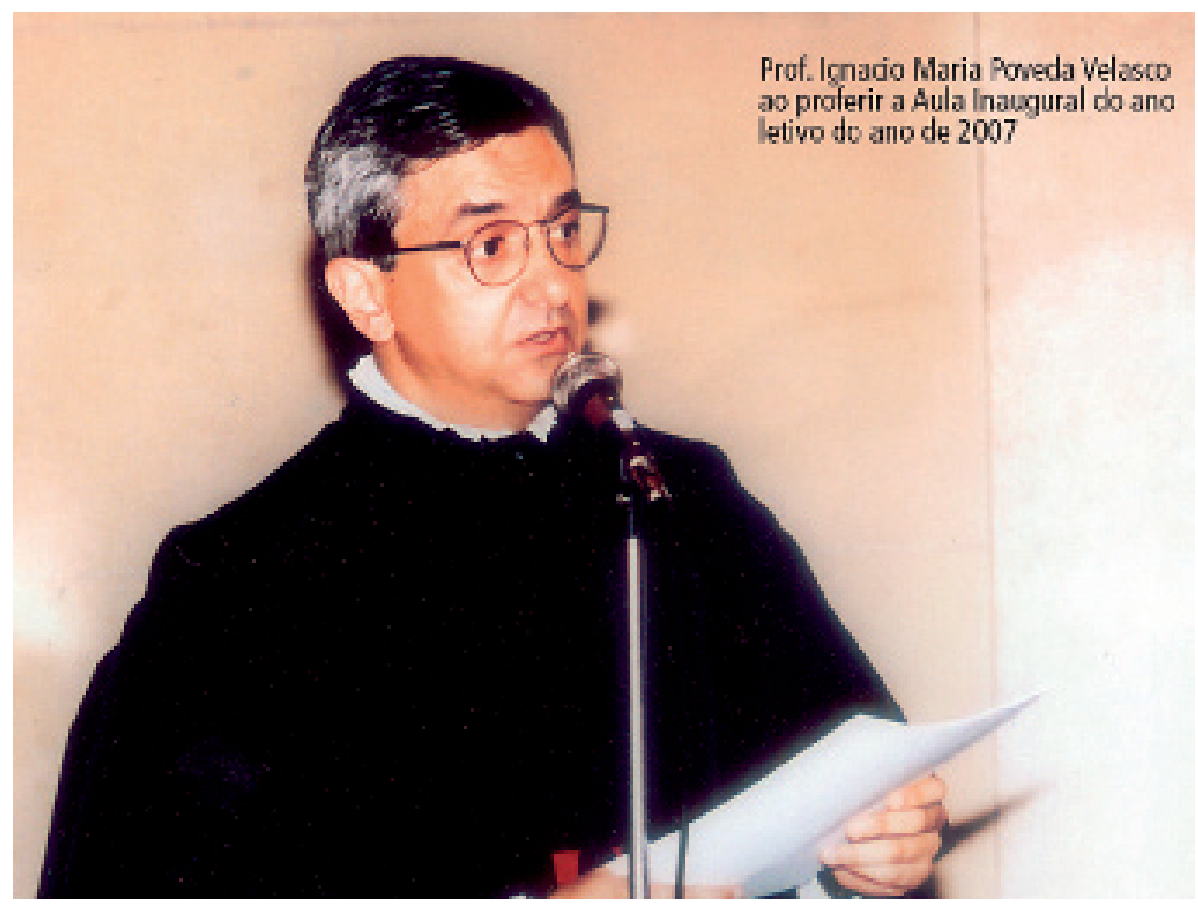

Professor Titular Ignacio Maria Poveda Velasco 